University of Wollongong

Research Online

Faculty of Engineering - Papers (Archive)

Faculty of Engineering and Information

Sciences

$1-1-2012$

\title{
Direct evidence of concurrent solid-solution and two-phase reactions and the nonequilibrium structural evolution of LiFePO 4
}

\author{
Neeraj Sharma \\ The Bragg Institute \\ Xianwei Guo \\ Chinese Academy of Sciences Beijing \\ Guodong Du \\ University of Wollongong,gd616@uow.edu.au \\ Zaiping Guo \\ University of Wollongong, zguo@uow.edu.au \\ Jiazhou Wang \\ University of Wollongong
}

See next page for additional authors

Follow this and additional works at: https://ro.uow.edu.au/engpapers

Part of the Engineering Commons

https://ro.uow.edu.au/engpapers/4459

\section{Recommended Citation}

Sharma, Neeraj; Guo, Xianwei; Du, Guodong; Guo, Zaiping; Wang, Jiazhou; Wang, Zhaoxiang; and Peterson, Vanessa K.: Direct evidence of concurrent solid-solution and two-phase reactions and the nonequilibrium structural evolution of LiFePO 4 2012, 7867-7873.

https://ro.uow.edu.au/engpapers/4459

Research Online is the open access institutional repository for the University of Wollongong. For further information contact the UOW Library: research-pubs@uow.edu.au 


\section{Authors}

Neeraj Sharma, Xianwei Guo, Guodong Du, Zaiping Guo, Jiazhou Wang, Zhaoxiang Wang, and Vanessa K. Peterson 


\title{
$\mathrm{J}$

\section{Direct Evidence of Concurrent Solid-Solution and Two-Phase Reactions and the Nonequilibrium Structural Evolution of $\mathrm{LiFePO}_{4}$}

\author{
Neeraj Sharma, ${ }^{\dagger} \dagger$ Xianwei Guo, ${ }^{\ddagger}$ Guodong Du, ${ }^{\S}$ Zaiping Guo, ${ }^{\S}$ Jiazhou Wang, ${ }^{\S}$ Zhaoxiang Wang, ${ }^{*, \neq}$ \\ and Vanessa K. Peterson*, ${ }^{\dagger}$
}

${ }^{\dagger}$ The Bragg Institute, Australian Nuclear Science and Technology Organisation, Locked Bag 2001, Kirrawee DC, New South Wales 2232, Australia

${ }^{\ddagger}$ Key Laboratory for Renewable Energy, Chinese Academy of Sciences \& Beijing Key Laboratory for New Energy Materials and Devices, Beijing National Laboratory for Condensed Matter Physics, Institute of Physics, Chinese Academy of Sciences, P. O. Box 603, Beijing 100190, China

${ }^{\S}$ Institute for Superconducting and Electronic Materials, University of Wollongong, Wollongong, New South Wales 2522, Australia

\section{Supporting Information}

ABSTRACT: Lithium-ion batteries power many portable devices and in the future are likely to play a significant role in sustainable-energy systems for transportation and the electrical grid. $\mathrm{LiFePO}_{4}$ is a candidate cathode material for second-generation lithium-ion batteries, bringing a high rate capability to this technology. $\mathrm{LiFePO}_{4}$ functions as a cathode where delithiation occurs via either a solid-solution or a two-phase mechanism, the pathway taken being influenced by sample preparation and electrochemical conditions. The details of the delithiation pathway and the relationship between the two-phase and solid-solution reactions remain controversial. Here we report, using real-time in situ neutron powder diffraction, the simultaneous occurrence of solid-solution and two-phase reactions after deep discharge in nonequilibrium conditions. This work is an example of the experimental investigation of nonequilibrium states in a commercially available $\mathrm{LiFePO}_{4}$ cathode and reveals the concurrent occurrence of and transition between the solid-solution and two-phase reactions.

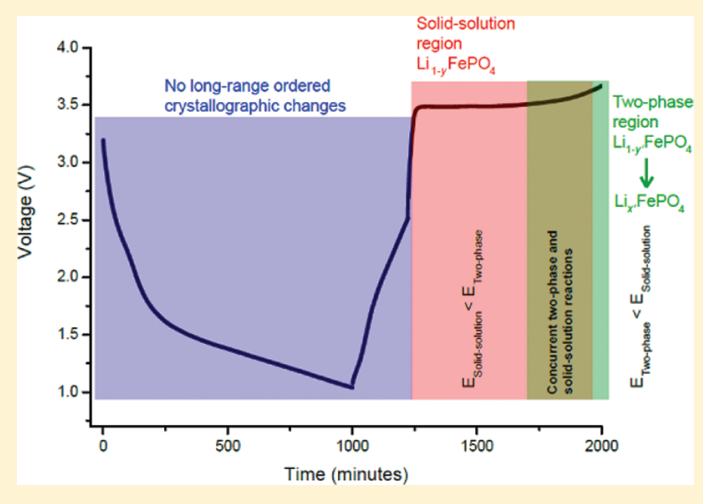

\section{INTRODUCTION}

$\mathrm{LiFePO}_{4}$ was first used as a cathode in lithium-ion batteries by Padhi et al. ${ }^{1}$ and has since featured in approximately 1400 cathode-related publications. $\mathrm{LiFePO}_{4}$ competes favorably with other commercial cathode materials, such as $\mathrm{LiCoO}_{2}$ and $\mathrm{LiMn}_{2} \mathrm{O}_{4},{ }^{2-4}$ because it is relatively cheap (depending on the synthesis route ${ }^{5}$ ), relatively environmentally benign, and can be tailored to produce good cycling performance and a high rate capability. ${ }^{6-8}$ The electrochemical functionality of $\mathrm{LiFePO}_{4}$ as a cathode can be interrogated using time-dependent experimentation ${ }^{9,10}$ that measures the structural evolution of $\mathrm{LiFePO}_{4}$, enabling the measurement of its reaction mechanisms.

Generally, industrial large-scale synthesis of $\mathrm{LiFePO}_{4}$ is tailored to minimize cost while maximizing performance and often results in a broad distribution of particle sizes, especially when a carbon-coating high-temperature anneal is used..$^{5}$ The particle size and morphology of $\mathrm{LiFePO}_{4}$ influences the lithium extraction and insertion mechanism ${ }^{11-13}$ that controls the performance characteristics of the cathode and the battery. ${ }^{14,15}$ The determination of the reaction mechanism of commercially produced $\mathrm{LiFePO}_{4}$ is a critical step in optimizing the performance of $\mathrm{LiFePO}_{4}$ as a battery cathode. Conventional solid-state synthesis at higher temperatures $\left(T=800{ }^{\circ} \mathrm{C}^{1}\right)$ yields $\mathrm{LiFePO}_{4}$ that undergoes a two-phase reaction, between $\mathrm{LiFePO}_{4}$ and $\mathrm{FePO}_{4}$, during charge (delithiation) and discharge (lithiation). ${ }^{1}$ Recently, $\mathrm{LiFePO}_{4}$ was shown to undergo delithiation and subsequent lithiation via a solid-solution reaction, ${ }^{14,15}$ and the reaction mechanism was linked to improved electrochemical behavior as a consequence of the lower stress and mechanical degradation relative to the twophase reaction. ${ }^{8,16}$ To date, solid-solution reactions have only been observed to occur for nanoparticles, highly defective nanoparticles (e.g., particles with $\mathrm{Li} / \mathrm{Fe}$ antisite mixing ${ }^{17}$ ), during heating of two-phase mixtures of $\mathrm{Li}_{x} \mathrm{FePO}_{4}$ with a range of particle-size distributions, ${ }^{11,18,19}$ and are theoretically predicted to occur under nonequilibrium conditions. ${ }^{8}$ To the best of our knowledge, only one theoretical study has investigated the interplay between the solid-solution and twophase reactions in $\mathrm{LiFePO}_{4}$ during charge/discharge; ${ }^{8}$ however, this work does not present experimental evidence for the transition between the two reactions. Signatures in the charge/ discharge curves have been associated with these two types of reactions, ${ }^{20}$ where a solid solution reaction produces a sloped

Received: February 6, 2012

Published: April 6, 2012 

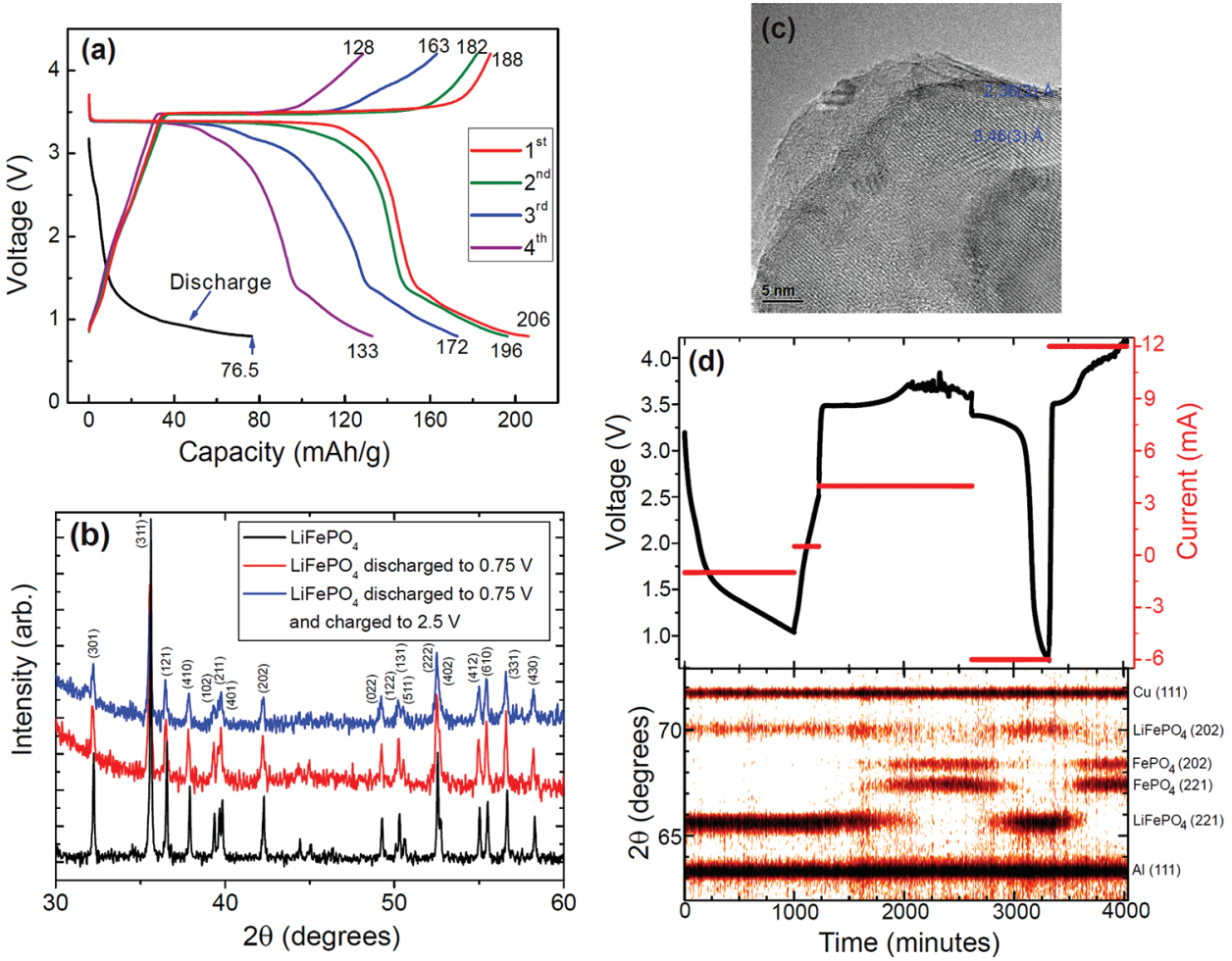

Figure 1. Characterization of $\mathrm{LiFePO}_{4}$ and its time-dependent electrochemical behavior: (a) galvanostatic charge/discharge voltage curves at 0.1 $\mathrm{mAh} \mathrm{g}^{-1}$ for $\mathrm{LilliFePO}_{4}$ coin cells discharged to $0.75 \mathrm{~V}$ and cycled between 0.75 and $4.2 \mathrm{~V}$ for four cycles; (b) ex situ XRPD patterns of the $\mathrm{LiFePO}_{4}$ cathode, the $\mathrm{LiFePO}_{4}$ cathode extracted after discharging to $0.75 \mathrm{~V}$, and the $\mathrm{LiFePO}_{4}$ cathode extracted after discharging to $0.75 \mathrm{~V}$ followed by charging to $2.5 \mathrm{~V}$; (c) ex situ TEM image of the $\mathrm{LiFePO}_{4}$ cathode extracted after discharging to $0.75 \mathrm{~V}$ with the regions producing the (201) and (410) $\mathrm{LiFePO}_{4}$ reflections or 2.36(3) and 3.46(3) Å interplane spacings labeled; (d) $62 \leq 2 \theta \leq 73^{\circ}$ region of in situ NPD data with scaled reflection intensity (bottom), applied current (red), and measured voltage (black).

increase/decrease in voltage (e.g., $\mathrm{LiMn}_{2} \mathrm{O}_{4}$ and $\mathrm{LiCoO}_{2}$ cathodes ${ }^{2-4}$ ) while a two-phase reaction produces a voltage plateau (e.g., first report on $\mathrm{LiFePO}_{4}{ }^{1}$ ). Although informative on the type of reaction taking place, these profiles yield little information concerning the mechanism of transformation between these reaction types. Our work directly measures the simultaneous occurrence of and transition between these reactions by probing the nature of the transition interface.

Conventionally, $\mathrm{LiFePO}_{4}$ is cycled between 2.5 and $4.2 \mathrm{~V}$, although recently $\mathrm{LiFePO}_{4}$ has been proposed to function as an anode through cycling to a lower voltage, and an all- $\mathrm{LiFePO}_{4}$ lithium-ion battery has been proposed. ${ }^{21,22}$ Theoretical calculations show that two additional lithium ions can be incorporated into $\mathrm{LiFePO}_{4}$, yielding " $\mathrm{Li}_{3} \mathrm{FePO}_{4}$ " as the product; ${ }^{21}$ however, such a compound will express metallic-

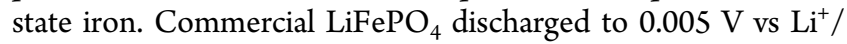
$\mathrm{Li}$ has been noted to feature charge storage on the grain boundaries of the metallic iron $/ \mathrm{Li}_{3} \mathrm{PO}_{4}$ nanocomposite that forms. ${ }^{23}$ In this work we investigate lithium insertion into $\mathrm{LiFePO}_{4}$ during deep discharge to $0.75 \mathrm{~V}$. Using real-time in situ neutron powder diffraction (NPD), during charge/ discharge we observe the coexistence of the solid-solution and two-phase reactions. A critical difference between our work and others is that the in situ NPD method measures changes in the bulk cathode, unlike the techniques of analysis used elsewhere such as electron microscopy, which probe only a few cathode particles. Therefore, NPD is uniquely sensitive to the distribution of phase fractions, including $\mathrm{LiFePO}_{4}$ and its delithiated products. Unlike ex situ experiments, ${ }^{13}$ timeresolved in situ NPD probes nonequilibrium states in the cathode, capturing the cathode response under real-world conditions, revealing mechanistic and structural information.

\section{RESULTS AND DISCUSSION}

The commercially available $\mathrm{LiFePO}_{4}$ used in this study has relatively large particles within an inhomogeneous and broad particle size distribution, as shown by scanning electron microscopy (SEM) (Figure S1 in the Supporting Information). Inductively coupled plasma atomic-emission spectrometry shows the carbon content of the $\mathrm{LiFePO}_{4}$ to be $1.9(5) \%$. Both the relatively large particle size and use of hightemperature synthetic heat treatment $\left(800{ }^{\circ} \mathrm{C}\right)$ are likely to minimize lithium/iron antisite mixing. ${ }^{17}$ The electrochemical performance of $\mathrm{LiFePO}_{4}$ changes significantly when cycled between 0.75 and $4.2 \mathrm{~V}$, relative to cycling between 2.5 and 4.2 $\mathrm{V}$ (Figure S2 in the Supporting Information). With discharge to $0.75 \mathrm{~V}$ and subsequent charging, the charge/discharge voltage curves (Figure 1a) show enhanced charge capacity that ultimately falls with further cycling. Improving $\mathrm{LiFePO}_{4}$ battery performance by maintaining a high capacity requires a thorough understanding of deep discharge processes, and this is the stimulus for our in situ structural studies.

Ex situ X-ray powder diffraction (XRPD) data collected from $\mathrm{LiFePO}_{4}$ extracted from coin cells at different states of charge (Figure 1b) show minimal line broadening but no major crystallographic changes upon discharge to $0.75 \mathrm{~V}$ and subsequent charge to $2.5 \mathrm{~V}$. An ex situ transmission electron microscopy (TEM) image of $\mathrm{LiFePO}_{4}$ extracted from coin cells that were discharged to $0.75 \mathrm{~V}$ shows no evidence of structural transformation (Figure 1c). No evidence for significant 
electrochemical milling of the $\mathrm{LiFePO}_{4}$ particles during deep discharge is observed in TEM images. In situ real-time NPD data show time-dependent crystal structure changes of $\mathrm{LiFePO}_{4}$ between 0.75 and $4.2 \mathrm{~V}$ (Figure 1d). We observe from $\sim 4 \mathrm{~V}(\mathrm{i})$ a $\mathrm{Li}_{x} \mathrm{FePO}_{4}$ solid-solution reaction, (ii) a $\mathrm{Li}_{x^{\prime}} \mathrm{FePO}_{4}-$ $\mathrm{Li}_{1-\gamma}, \mathrm{FePO}_{4}$ two-phase reaction, (iii) a combination of $\mathrm{Li}_{x^{\prime}}, \mathrm{FePO}_{4}-\mathrm{Li}_{1-y}, \mathrm{FePO}_{4}$ two-phase and $\mathrm{Li}_{1-y} \mathrm{FePO}_{4}$ solidsolution reactions, (iv) a $\mathrm{Li}_{1-y} \mathrm{FePO}_{4}$ solid-solution reaction, and (v) no long-range-ordered structural changes below $\sim 3.4 \mathrm{~V}$ (Figure 2). The sequence of these reaction mechanisms with

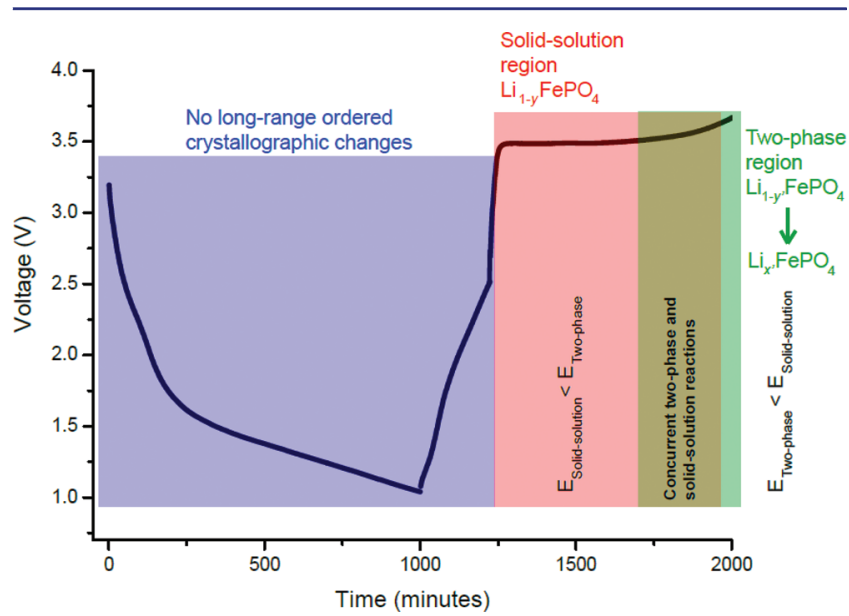

Figure 2. Electrochemical reaction mechanisms of $\mathrm{LiFePO}_{4}$ measured using in situ NPD. Mechanisms include no long-range crystallographic changes between 0.75 and $3.42 \mathrm{~V}$, a solid-solution reaction $\left(\mathrm{Li}_{1-y} \mathrm{FePO}_{4}\right)$ between 3.42 and $3.52 \mathrm{~V}$, a two-phase reaction $\left(\mathrm{Li}_{1-y} \mathrm{FePO}_{4}\right.$ to $\left.\mathrm{Li}_{x^{\prime}} \mathrm{FePO} \mathrm{PeP}_{4}\right)$ between 3.49 and $3.67 \mathrm{~V}$, and a solidsolution reaction at higher voltages (not shown) producing $\mathrm{FePO}_{4}$. The green-brown region shows a transition between solid-solution and two-phase reactions, where both reactions are observed concurrently. Reaction mechanisms between 0.75 and $4.2 \mathrm{~V}$ are reproducible at applied current rates of 3.4 and $12 \mathrm{~mA}$. E is an indicator of the relative amount of energy required for a reaction to proceed. charge/discharge is reproducible at higher currents. Discharging a fresh $\mathrm{LilliFePO}$ battery to 0.75 or $1 \mathrm{~V}$ and subsequently charging to $\sim 3.4 \mathrm{~V}$ does not cause any changes in the bulk long-range crystal structure (Figure 1d). This observation agrees with ex situ XRPD (Figure $1 \mathrm{~b}$ ) and TEM results (Figure $1 c)$.

The NPD data indicate that no portion of the cathode underwent long-range crystal structural changes during the deep discharge, with Rietveld analysis and Gaussian fits to the $\mathrm{LiFePO}_{4}$ (221) reflection (Figures 3 and 4) during the lowvoltage discharge $(0.75-3.42 \mathrm{~V})$ indicating a relatively static crystal volume for this phase. Therefore, mechanisms other than crystal-structure changes must be responsible for the observed behavior. Such other mechanisms may involve surface-mediated reactions on grain boundaries or interfaces. $^{24,25}$ Surface-mediated reactions can assist in trapping lithium ions during the low-voltage discharge, and these trapped lithium ions may be released during charge, enhancing charge capacity and influencing the reaction mechanisms occurring during charging (Figure 2), favoring the solidsolution reaction over the two-phase reaction. Under such a regime, further charging may cause the solid-solution reaction to transition to a two-phase reaction as the latter becomes more favorable when the surface-trapped lithium is removed.

Changes in the position of the $\mathrm{LiFePO}_{4}$ (221) reflection and the failure of any $\mathrm{FePO}_{4}$ reflections to appear indicate that the delithiation of $\mathrm{LiFePO}_{4}$ occurs via a solid-solution reaction $\left(\mathrm{Li}_{1-y} \mathrm{FePO}_{4}\right)$ between 3.42 and $3.52 \mathrm{~V}$ (shaded region in Figure 3a). Given the relatively large particles in the $\mathrm{LiFePO}_{4}$ electrode, further confirmed by the relatively narrow peaks in the XRPD and in situ NPD data, we expect only a two-phase reaction during charge/discharge. ${ }^{1}$ We note that the smaller particles $(<10 \mathrm{~nm})$ in this commercial sample can result in NPD peak broadening. Given the relatively small $(<10 \%)$ amount of such particles, these are not expected to contribute to the measured NPD signal. Similarly, these are not expected to contribute significantly to the battery performance. In addition, the full width at half-maximum of the $\mathrm{LiFePO}_{4}(221)$ (a)

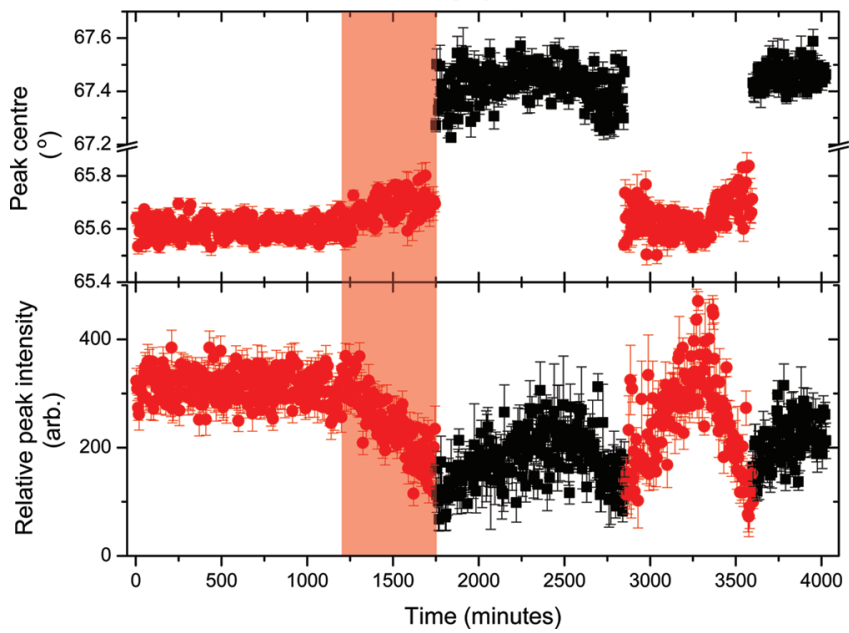

(b)

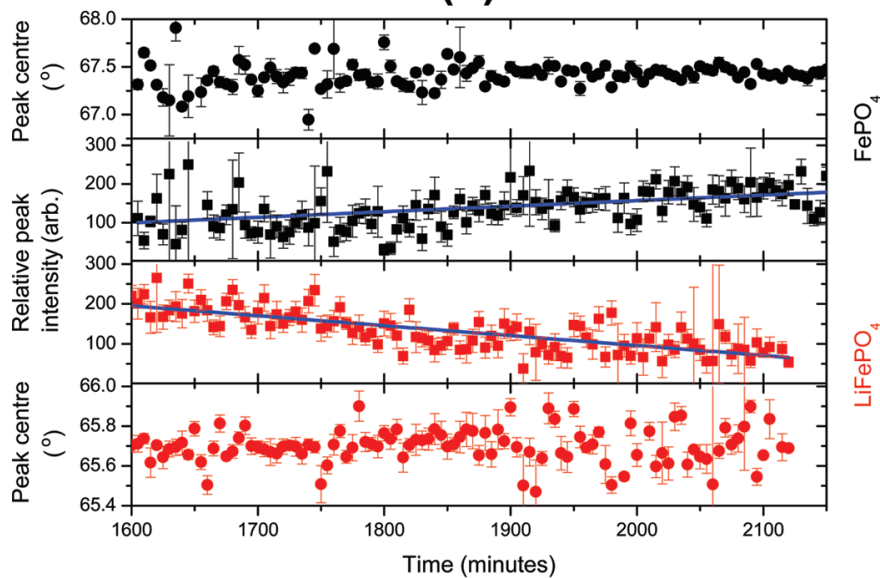

Figure 3. Results of Gaussian fits to the $\mathrm{LiFePO}_{4}$ and $\mathrm{FePO}_{4}(221)$ reflections in the in situ NPD data. (a) Changes in the $2 \theta$ value and the integrated intensity of the $\mathrm{LiFePO}_{4}$ and $\mathrm{FePO}_{4}(221)$ reflections, with red circles denoting $\mathrm{LiFePO}_{4}$ and $\mathrm{Li}_{1-y} \mathrm{FePO}_{4}$ and black squares denoting $\mathrm{FePO}_{4}$ and $\mathrm{Li}_{x} \mathrm{FePO}_{4}$. The shaded region represents the region of the first solid-solution reaction. (b) Results of Gaussian fits in the region where solid-solution $\left(\mathrm{Li}_{1-y} \mathrm{FePO}_{4}\right)$ and two-phase $\left(\mathrm{Li}_{1-y} \mathrm{FePO}_{4}\right.$ to $\left.\mathrm{Li}_{x^{\prime}} \mathrm{FePO}_{4}\right)$ reactions occur concurrently. Linear blue lines are shown as a guide to the eye. 


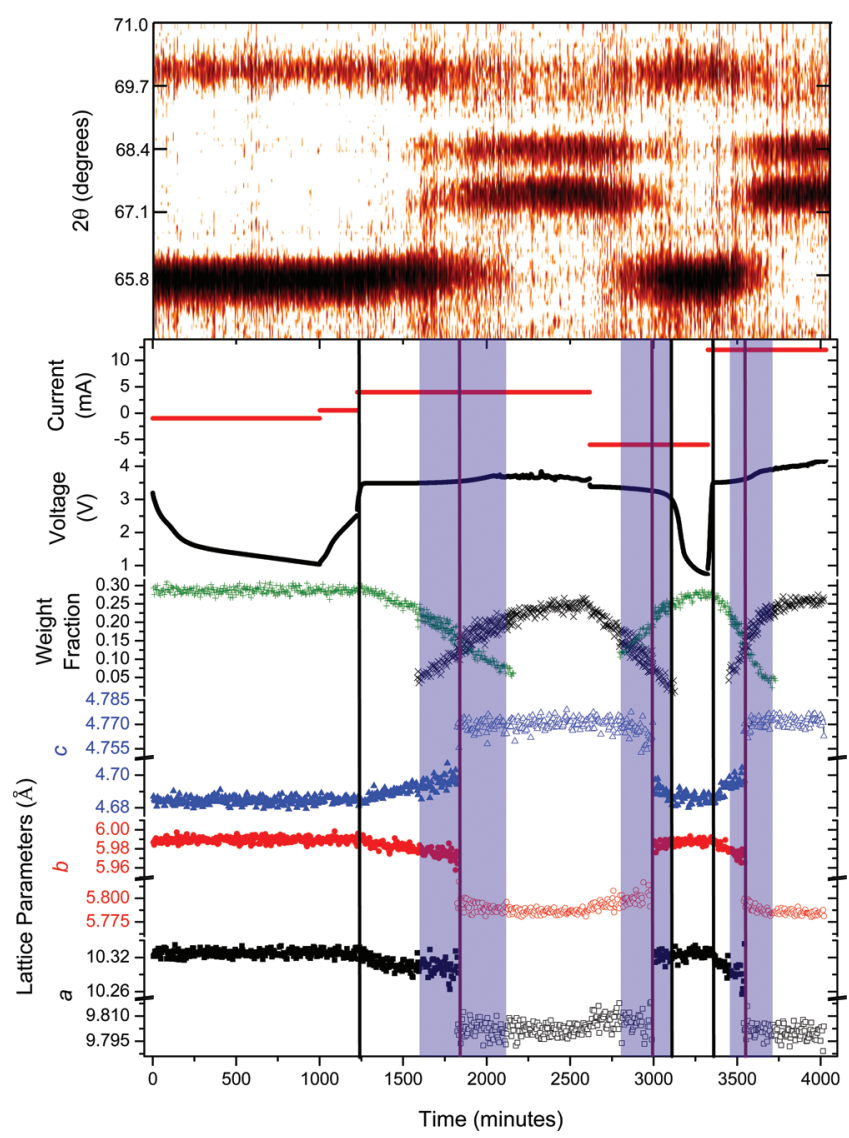

Figure 4. In situ NPD data of the $\mathrm{LilliFePO}_{4}$ battery and Rietveldderived lattice parameters of the cathode. Selected $2 \theta$ region of in situ NPD data (top) with scaled intensity highlighting the $\mathrm{LiFePO}_{4}$ and $\mathrm{FePO}_{4}(221)$ and (202) reflections. The applied current is the red line, and the measured voltage is the black line. Parameters derived from Rietveld refinements are the phase fraction of $\mathrm{LiFePO}_{4}$ (green crosses), the phase fraction of $\mathrm{FePO}_{4}$ (black crosses), and the phase lattice parameters, where $a$ is black, $b$ is red, and $c$ is blue. The lattice parameters for $\mathrm{LiFePO}_{4}$ are solid symbols and for $\mathrm{FePO}_{4}$ are open symbols. Vertical black lines represent the onset of the solid-solution reaction, and vertical purple lines indicate the chronological transition from a composition that is predominantly $\mathrm{Li}_{1-y} \mathrm{FePO}_{4}$ to predominantly $\mathrm{Li}_{x} \mathrm{FePO}_{4}$. Shaded regions indicate the coexistence of solidsolution and two-phase reactions.

reflection in the NPD data does not change during the solidsolution reaction. We postulate that the solid-solution reaction in this sample is "activated" by the low-voltage discharge (Figure 2).

Our time-dependent data show that the solid-solution and two-phase reactions occur concurrently between 3.49 and 3.52 $\mathrm{V}$ (Figure $3 \mathrm{~b}$ ). The concurrent solid-solution and two-phase reactions are indicated by the appearance and subsequent increasing intensity of the $\mathrm{FePO}_{4}(221)$ reflection at the same time as the $\mathrm{LiFePO}_{4}(221)$ reflection changes position. During the concurrent solid-solution and two-phase reactions the intensity of the $\mathrm{FePO}_{4}$ (221) reflection increases at a rate of $0.14(2)$ relative intensity unit $/ \mathrm{min}$ and the $2 \theta$ value changes at a rate of $0.14(5) \times 10^{-4}\left({ }^{\circ}\right) / \mathrm{min}$, while the $\mathrm{LiFePO}_{4}(221)$ reflection intensity decreases at a rate of $0.25(2)$ relative peak intensity unit/min and the $2 \theta$ value changes at a rate of $3(6) \times$ $10^{-5}\left(^{\circ}\right) / \mathrm{min}$. The increase in $2 \theta$ value of the $\mathrm{LiFePO}_{4}(221)$ reflection corresponds to a decrease in the unit-cell volume of $\mathrm{LiFePO}_{4}$. Our results indicate a reaction mechanism in which part of the $\mathrm{LiFePO}_{4}$ is transformed, via a solid-solution reaction, to $\mathrm{Li}_{1-y} \mathrm{FePO}_{4}$, where $y^{\prime}$ represents the lithium content of the $\mathrm{Li}_{1-y} \mathrm{FePO}_{4}$ solid solution at which the transition to the two-phase reaction (at 3.49-3.67 V) begins. The solid-solution reaction transitions to the two-phase reaction occurring between $\mathrm{Li}_{1-y^{\prime}} \mathrm{FePO}_{4}$ and $\mathrm{Li}_{x^{\prime}} \mathrm{FePO}_{4}$ where $x^{\prime}$ is the critical lithium content of the lithium-poor $\mathrm{Li}_{x} \mathrm{FePO}_{4}$ (Figure 2), from which another solid-solution reaction begins at higher voltages. Interestingly, our nonequilibrium data show that part of the $\mathrm{LiFePO}_{4}$ cathode continues to undergo a solid-solution reaction while another part of the cathode undergoes a twophase reaction in the transition period between the reaction mechanisms. The existence of a solid-solution reaction is an important consideration for electrode performance, as this reaction has been shown to influence significantly the kinetics of the $\mathrm{LiFePO}_{4}$ cathode. ${ }^{8}$

Voltage fluctuations are observed in the first charge cycle between 2100 and $2600 \mathrm{~min}$ (Figure 1d) and are attributed to the use of deuterated carbonates in the electrolyte, as noted in previous work. ${ }^{26}$ The discharge process of the $\mathrm{LilliFePO}_{4}$ battery follows a structural and electrochemical path inverse to the charging processes that are described earlier. Sequential multiphase Rietveld refinements were performed using models of $\mathrm{LiFePO}_{4},{ }^{1} \mathrm{FePO}_{4},{ }^{1} \mathrm{Al}^{27} \mathrm{Cu}^{28}$ and $\mathrm{Li}^{29}$ using the in situ NPD data. The time-dependent evolution of the Rietveldrefined lattice parameters and phase fractions of $\mathrm{LiFePO}_{4}$ and $\mathrm{FePO}_{4}$, along with the voltage and applied current, for a selected region of the in situ NPD data are shown in Figure 4. The onset of a solid-solution reaction is indicated by the vertical black lines, and the vertical purple lines indicate the midpoint of the two-phase reaction where the second phase is quantitatively proportional to, or larger than, the first phase. The blue shading identifies regions where solid-solution and two-phase reactions occur concurrently. The lattice parameters for the $\mathrm{LiFePO}_{4}$ and $\mathrm{FePO}_{4}$ phases are illustrated by the closed and open symbols, respectively, in Figure 4. Rietveld refinement of the $\mathrm{LiFePO}_{4}$ lattice parameters reveals that $a$ contracts by $0.01(1) \AA, b$ contracts by $0.012(7) \AA$, and $c$ expands by $0.011(6) \AA$ during the solid-solution reaction $(3.42-3.52 \mathrm{~V})$, which quantitatively agrees with the previously measured and predicted lattice parameters. ${ }^{30}$ The variation in the $\mathrm{LiFePO}_{4} /$ $\mathrm{FePO}_{4}$ phase fractions evidences the two-phase reaction and the change in the $\mathrm{Li}_{1-y} \mathrm{FePO}_{4}$ (and $\mathrm{Li}_{x} \mathrm{FePO}_{4}$ ) lattice parameters evidences the solid-solution reaction, both of which occur simultaneously in the shaded region in Figure 4.

The miscibility gap for $\mathrm{LiFePO}_{4}$ was evaluated using Vegard's law, ${ }^{15}$ and we find that $y \approx 0.04$ for $\mathrm{Li}_{1-y} \mathrm{FePO}_{4}$ and $x \approx 0.03$ for $\mathrm{Li}_{x} \mathrm{FePO}_{4}$. The asymmetry in the miscibility gap is consistent with our hypothesis of the "activation" of the solid-solution reaction by the deep discharge to $0.75 \mathrm{~V}$, where a larger solid-solution region for $\mathrm{Li}_{1-y} \mathrm{FePO}_{4}$ is observed, relative to $\mathrm{Li}_{x} \mathrm{FePO}_{4}$. Asymmetric behavior is also noted for the kinetics of lithium insertion and extraction, ${ }^{31}$ where the kinetics of lithium insertion are more limited (slower) than the kinetics for lithium extraction, which is analogous to the unequal solidsolution ranges $(\Delta x \neq \Delta y)$ observed here. We show that the rate of change of the $\mathrm{LiFePO}_{4}$ lattice during the $\mathrm{Li}_{1-y} \mathrm{FePO}_{4}$ solid-solution reaction is $-4.3(4) \times 10^{-5} \AA / \mathrm{min}$ for $a,-2.7(1)$ $\times 10^{-5} \AA / \mathrm{min}$ for $b$, and $2.1(1) \times 10^{-5} \AA / \mathrm{min}$ for $c$, at applied currents of $3.4 \mathrm{~mA}$. At applied currents of $12 \mathrm{~mA}$ the lattice changes by $-2.1(2) \times 10^{-4} \AA / \mathrm{min}$ for $a,-8.6(7) \times 10^{-5} \AA /$ min for $b$, and $7.8(8) \times 10^{-5} \AA / \mathrm{min}$ for $c$. Hence, the rate of lattice parameter change is directly proportional to the applied 
current, with an approximate factor of 4 increase in the rate of lattice parameter change corresponding to an increase in current of approximately a factor of 4 .

Critical phenomena presented here include the bulk transformation of $\mathrm{LiFePO}_{4}$ to $\mathrm{Li}_{1-y} \mathrm{FePO}_{4}$, the observation of solid-solution and two-phase reactions occurring concurrently, and the critical value of $y\left(y^{\prime}\right)$ at which $\mathrm{Li}_{1-y^{\prime}} \mathrm{FePO}_{4}$ transforms to $\mathrm{Li}_{x^{\prime}} \mathrm{FePO}_{4}$ via a two-phase reaction. The critical value for $y^{\prime}$ is between $\sim 0.01$ (where the first $\mathrm{Li}_{x}, \mathrm{FePO}_{4}$ is observed) and $\sim 0.04$ (the final composition of $\mathrm{Li}_{1-y} \mathrm{FePO}_{4}$ in the solidsolution region). To describe the concurrent solid-solution and two-phase reactions, as well as the transition from solidsolution to two-phase reactions, mechanistic approaches $1,9,16,17,31-36$ to modeling the phase boundaries and the $\mathrm{LiFePO}_{4}$ to $\mathrm{FePO}_{4}$ transition need to be modified. The first model we consider is the shrinking-core model, ${ }^{1}$ where the $\mathrm{LiFePO}_{4}$ particle or agglomerate of particles ${ }^{32}$ transforms to $\mathrm{FePO}_{4}$ from the outer shell of the particle to the core. The second model that we consider is the core-shell model, where the $\mathrm{LiFePO}_{4}$ particle transforms anisotropically and the "core" is $\mathrm{FePO}_{4}$ as a result of the smaller lattice parameter of $\mathrm{FePO}_{4}$, relative to $\mathrm{LiFePO}_{4}$, with the latter remaining at the shell. ${ }^{31}$ Neither the shrinking-core nor the core-shell models, which only consider single particles, can be directly applied to our observations. We observe that the majority of the $\mathrm{LiFePO}_{4}$ particle(s) transform completely to $\mathrm{Li}_{1-y} \mathrm{FePO}_{4}$, after which the solid-solution reaction continues until the composition $\mathrm{Li}_{1-y} \mathrm{FePO}_{4}$, whereby the transformation to $\mathrm{Li}_{x^{\prime}}, \mathrm{FePO}_{4}$ occurs via a two-phase reaction (consistent with our observation of concurrent solid-solution and two-phase reactions). A modified shrinking-core model ${ }^{1}$ with spherical particles would result in the solid-solution transformation of bulk $\mathrm{LiFePO}_{4}$ to $\mathrm{Li}_{1-y} \mathrm{FePO}_{4}$. Where this solid solution forms $\mathrm{Li}_{1-y^{\prime}} \mathrm{FePO}_{4}$, the two-phase reaction is initiated, converting $\mathrm{Li}_{1-y}, \mathrm{FePO}_{4}$ to $\mathrm{Li}_{x^{\prime}}, \mathrm{FePO}_{4}$, while the $\mathrm{Li}_{1-y} \mathrm{FePO}_{4}$ solid solution proceeds to the core. A modified core-shell model ${ }^{31}$ featuring anisotropic particles would result in phases nucleating at the "core", first to $\mathrm{Li}_{1-y} \mathrm{FePO}_{4}$, then to $\mathrm{Li}_{1-y}, \mathrm{FePO}_{4}$, and finally to $\mathrm{Li}_{x}, \mathrm{FePO}_{4}$, moving toward the particle boundary. In the case of the coreshell model the two-phase interface at the reaction front is described as a linear combination of $\mathrm{LiFePO}_{4}$ and $\mathrm{FePO}_{4}$ end members, ${ }^{31}$ whereas we observe a linear combination of $\mathrm{Li}_{1-y} \mathrm{FePO}_{4}$ and $\mathrm{Li}_{x}, \mathrm{FePO}_{4}$. A major drawback of the shrinking-core and core-shell models to describe the evolution of the reaction mechanisms that we observe experimentally is the necessity for the majority of particles to be at similar degrees of lithiation. Since our cathode contains a distribution of particle sizes, it is unlikely that the majority of particles meet this requirement.

Although models based on the core-shell approach are widely used, the domino-cascade model $^{32}$ presents a different approach to both the core-shell and shrinking-core models, with the multiple-particle domino-cascade model best describing our in situ NPD observations (Figure 5). Atomic-level structural distortions are proposed in the domino-cascade model, where a site nucleated within a $\mathrm{LiFePO}_{4}$ particle transforms to $\mathrm{FePO}_{4}$ so rapidly that the whole particle transforms before further nucleation sites are generated. The reaction mechanism is found to be affected by particle size, where the particle size determines whether two-phase reactions can be stabilized within a particle. ${ }^{8,12,34}$ Macroscopically, a modified domino-cascade model can be reconciled with our observations by considering the $\mathrm{LiFePO}_{4}$ cathode as a (i)

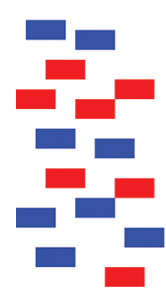

(ii)

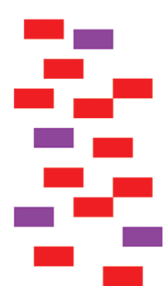

(iii)

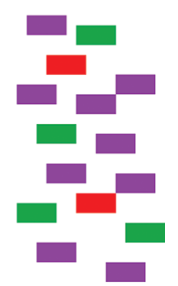

Figure 5. Schematic of the macroscopic domino-cascade model ${ }^{32}$ of the $\mathrm{LiFePO}_{4}$ to $\mathrm{FePO}_{4}$ transition, adapted to account for mechanisms observed using in situ NPD, incorporating the concurrent solidsolution and two-phase reactions. Mechanisms for lithium extraction are shown in two-dimensional cross sections (left to right). In (i) $\mathrm{LiFePO}_{4}$ particles (blue) transform to $\mathrm{Li}_{1-y} \mathrm{FePO}_{4}$ (red) via the solidsolution reaction. In (ii) all $\mathrm{LiFePO}_{4}$ is transformed to $\mathrm{Li}_{1-y} \mathrm{FePO}_{4}$ and a portion of $\mathrm{Li}_{1-y} \mathrm{FePO}_{4}$ particles exist with the $\mathrm{Li}_{1-y^{\prime}} \mathrm{FePO}_{4}$ composition (purple), and in (iii) a portion of the $\mathrm{Li}_{1-y}, \mathrm{FePO}_{4}$ particles are transformed to $\mathrm{Li}_{x} \mathrm{FePO}_{4}$ (green) via the two-phase reaction.

distribution of particles, as shown in Figure 5. In the domino-cascade model, applied to our data for $\mathrm{LiFePO}_{4}$ on charging, the bulk of the $\mathrm{LiFePO}_{4}$ particles of the pristine cathode transform to $\mathrm{Li}_{1-y} \mathrm{FePO}_{4}$, where $y \leq y^{\prime}$, via a rapid transition, occurring as a solid-solution rather than a two-phase reaction. More particles transform to $\mathrm{Li}_{1-y} \mathrm{FePO}_{4}$ on further charging, a selection of which transition to $\mathrm{Li}_{x}, \mathrm{FePO}_{4}$, consistent with the observed concurrent solid-solution and two-phase reactions. This mechanism can incorporate reactions which are simultaneous or occur by a two-step process within a particle, e.g. solid-solution followed by two-phase reactions, both of which are consistent with our observations of transformations within the bulk $\mathrm{LiFePO}_{4}$ cathode. Our data do not allow us to delineate between multiple domains within crystallites or a distribution of crystallites with varying values of $y$. Wagemaker et al. ${ }^{12}$ suggest that a cathode with a distribution of particle sizes (as studied here) may feature particles at different states of lithiation for a particular state of charge of the battery, which is consistent with our observations.

\section{- CONCLUSIONS}

We provide direct experimental evidence for competitive solidsolution and two-phase reactions occurring within a $\mathrm{LiFePO}_{4}$ cathode under nonequilibrium conditions, as theoretically predicted. ${ }^{12,34}$ Our real-time studies overcome the uncertainties that may be introduced in ex situ studies as a result of the battery history, a problem in earlier work. ${ }^{37}$ The in situ NPD technique is sensitive to bulk crystallographic changes in the cathode, and we observe solid-solution and two-phase reactions occurring concurrently, the reactions for both being dependent on particle size, the delithiation/lithiation technique (chemical or electrochemical), and applied-current rate. In situ techniques provide data that allow reaction models to be determined and reveal the lithium insertion/extraction mechanisms in $\mathrm{LiFePO}_{4}$. Using in situ NPD data, we show how the modified shrinkingcore, core-shell, and domino-cascade models can be used to describe experimental observations. $\mathrm{LiFePO}_{4}$ "activation" during discharging to $0.75 \mathrm{~V}$ is proposed, at least in part, to induce the observed solid-solution reaction, which is known to significantly influence battery performance. Solid-solution reactions, and the transition between the solid-solution and two-phase reaction, are observed using time-dependent in situ 
NPD. The $\mathrm{Li}_{1-y} \mathrm{FePO}_{4}$ solid-solution extends to $y \approx 0.04$, whereas $\mathrm{Li}_{x} \mathrm{FePO}_{4}$ extends to $x \approx 0.03$, with the asymmetry in the solid solution domains is a consequence of the $0.75 \mathrm{~V}$ discharge. Moreover, the rate of lattice parameter change during the $\mathrm{Li}_{1-y} \mathrm{FePO}_{4}$ solid-solution reaction directly correlates to the applied current. Finally, the sequence of the reactions occurring in our $\mathrm{LiFePO}_{4}$ electrodes is preserved in subsequent cycles (with discharge to $0.75 \mathrm{~V}$ ) and using higher applied currents.

\section{EXPERIMENTAL SECTION}

Materials and Preliminary Characterization. $\mathrm{LiFePO}_{4}$ samples with a carbon content of $1.85(2)$ wt $\%$ were used as purchased from Tianjin STL Energy Technology Co., Ltd., with the size of the primary particles given as $0.5-1 \mu \mathrm{m}$. Scanning electron microscopy (Hitachi S4000 ) and X-ray powder diffraction (X'Pert Pro MPD, using $\mathrm{Cu} \mathrm{K} \alpha$ radiation) were used to verify the phase purity. The sample consisted of relatively large micrometer-sized particles, presumably generated from the high-temperature synthesis $\left(800{ }^{\circ} \mathrm{C}\right)$, which is expected to minimize $\mathrm{Fe} / \mathrm{Li}$ antisite disorder. Inductively coupled plasma atomic emission spectroscopy (Thermo Scientific) analysis was used to determine a carbon content of $1.9(5) \%$ and the Li:Fe:P ratio of 0.93(1):0.97(1):1. Ex situ transmission electron microscopy (TEM, Tecnai G2 F20 U-TWIN) analysis of the $\mathrm{LiFePO}_{4}$ electrode was performed on $\mathrm{LiFePO}_{4}$ extracted from the battery, rinsed with dimethyl carbonate (DMC), placed under vacuum overnight, and then dispersed in DMC ultrasonically, followed by transfer to a copper grid. These procedures were undertaken in an argon-containing glovebox. Exposure to air was minimized by undertaking a fast sample transfer to the TEM.

Ex Situ Electrochemical Cycling. Coin-cell tests were performed on a working electrode fabricated from a $\mathrm{N}$-methylpyrrolidone slurry containing $80 \mathrm{wt} \% \mathrm{LiFePO}_{4}$ powder, $10 \mathrm{wt} \%$ carbon black (CB), and $10 \mathrm{wt} \%$ polyvinylidene fluoride (PVDF) binder cast on a titanium foil. Electrodes containing 5 wt \% $\mathrm{CB}$ were also prepared for use as a reference. Coin cells were assembled in an argon-filled glovebox using a $1 \mathrm{M}$ solution of lithium hexafluorophosphase in ethylene carbonate (EC)/DMC $(1 / 1 \mathrm{v} / \mathrm{v})$ as the electrolyte, lithium foil as the counter electrode, and Celgard 2300 as the separator. The electrochemical performance of the $\mathrm{LiFePO}_{4}$ battery was recorded using a Land BT200 battery tester at a current density of $0.1 \mathrm{mAh} \mathrm{g}^{-1}$.

In Situ NPD Electrochemical Cell Construction. Composite electrodes used in the in situ NPD experiment were made by mixing $\mathrm{LiFePO}_{4}$ with $\mathrm{CB}$ and PVDF to form a paste. The paste was applied to an aluminum sheet and dried in a vacuum oven overnight at $110^{\circ} \mathrm{C}$. The electrochemical cell ${ }^{38,39}$ was assembled in an argon-containing glovebox with layers of materials arranged in the following order: Celgard (insulator), $\mathrm{LiFePO}_{4}$ paste on aluminum, Celgard (separator), and lithium metal. Copper wire was placed in contact with the lithium and aluminum in contact with the cathode. This assembly was rolled using the outer Celgard layer and inserted into a $9 \mathrm{~mm}$ diameter vanadium can. The electrolyte was $1 \mathrm{M}$ lithium hexafluorophosphate in a $1 / 1 \mathrm{vol} \%$ mixture of deuterated EC (CDN, chemical purity $99.3 \%$ and isotopic purity 99\%) and deuterated DMC (Cambridge Isotopes, chemical purity $98 \%$ and isotopic purity $99 \%$ ). The electrolyte was added to the vanadium can, which was then sealed with wax.

\section{ASSOCIATED CONTENT}

\section{S Supporting Information}

Figures showing a scanning electron microscopy image of $\mathrm{LiFePO}_{4}$ and electrochemical cycling of $\mathrm{LiFePO}_{4}$ under conventional conditions and text describing details of the neutron powder diffraction data collection and analysis. This material is available free of charge via the Internet at http:// pubs.acs.org.

\section{AUTHOR INFORMATION}

\section{Corresponding Author}

*V.K.P.: e-mail, vanessa.peterson@ansto.gov.au; tel, +61-29717-9401; fax, +61-2-9717-3606. Z.W.: e-mail, zxwang@iphy. ac.cn; tel, +86-10-8264-9050. N.S.: e-mail, n.sharma@ansto. gov.au; tel, +61 297177253 .

\section{Notes}

The authors declare no competing financial interest.

\section{ACKNOWLEDGMENTS}

Part of this project was supported by the Australian Research Council (ARC) through the ARC Discovery project DP1094261. The infrastructure and materials for the experiments were in part provided by the ANSTO funded "Neutrons for the Hydrogen Economy (Energy)" research project within the Bragg Institute.

\section{REFERENCES}

(1) Padhi, A. K.; Nanjundaswamy, K. S.; Goodenough, J. B. J. Electrochem. Soc. 1997, 144, 1188.

(2) Nagaura, T.; Tozawa, K. Prog. Batteries Solar Cells 1990, 9, 209.

(3) Guyomard, D.; Tarascon, J.-M. Solid State Ionics 1994, 69, 222.

(4) Thackeray, M. M.; de Kock, A.; Rossouw, M. H.; Liles, D.; Bittihn, R.; Hoge, D. J. Electrochem. Soc. 1992, 139, 363.

(5) Tarascon, J.-M.; Recham, N.; Armand, M.; Chotard, J.-N.; Barpanda, P.; Walker, W.; Dupont, L. Chem. Mater. 2010, 22, 724.

(6) Tarascon, J.-M.; Armand, M. Nature 2001, 414, 359.

(7) Chung, S. Y.; Bloking, J. T.; Chiang, Y. M. Nat. Mater. 2002, 1, 123.

(8) Malik, R.; Zhou, F.; Ceder, G. Nat. Mater. 2011, 10, 587.

(9) Gu, L.; Zhu, C.; Li, H.; Yu, Y.; Li, C.; Tsukimoto, S.; Maier, J.; Ikuhara, Y. J. Am. Chem. Soc. 2011, 133, 4661.

(10) Jones, J.; Hung, J.-T.; Meng, Y. S. J. Power Sources 2009, 189, 702 .

(11) Ellis, B. L.; Lee, K. T.; Nazar, L. F. Chem. Mater. 2010, 22, 691.

(12) Wagemaker, M.; Singh, D. P.; Borghols, W. J. H.; Lafont, U.; Haverkate, L.; Peterson, V. K.; Mulder, F. M. J. Am. Chem. Soc. 2011, 133,10222 .

(13) Kobayashi, G.; Nishimura, S.; Park, M.; Kanno, R.; Yashima, M.; Ida, T.; Yamada, A. Adv. Funct. Mater. 2009, 19, 395.

(14) Yamada, A.; Koizumi, H.; Sonoyama, N.; Kanno, R. Electrochem. Solid-State Lett. 2005, 8, A409.

(15) Meethong, N.; Huang, H. Y. S.; Carter, W. C.; Chiang, Y. M. Electrochem. Solid-State Lett. 2007, 10, A134.

(16) Yamada, A.; Koizumi, H.; Nishimura, S.; Sonoyama, N.; Kanno, R.; Yonemura, M.; Nakamura, T.; Kobayashi, Y. Nat. Mater. 2006, 5, 357.

(17) Gibot, P.; Casas-Cabanas, M.; Laffont, L.; Levasseur, S.; Carlach, P.; Hamelet, S.; Tarascon, J.-M.; Masquelier, C. Nat. Mater. 2008, 7, 741.

(18) Delacourt, C.; Poizot, P.; Tarascon, J.-M.; Masquelier, C. Nat. Mater. 2005, 4, 254.

(19) Nishimura, S.; Kobayashi, G.; Ohoyama, K.; Kanno, R.; Yashima, M.; Yamada, A. Nat. Mater. 2008, 7, 707.

(20) Goodenough, J. B.; Kim, Y. J. Power Sources 2011, 196, 6688.

(21) Ouyang, C. Y.; Shi, S. Q.; Fang, Q.; Lei, M. S. J. Power Sources 2008, 175, 891.

(22) Kalaiselvi, N.; Doh, C. H.; Park, C. W.; Moon, S. I.; Yun, M. S. Electrochem. Commun. 2004, 6, 1110.

(23) Guo, X. W.; Fang, X. P.; Mao, Y.; Wang, Z. X.; Wu, F.; Chen, L. Q. J. Phys. Chem. C 2011, 115, 3803.

(24) Poizot, P.; Laruelle, S.; Grugeon, S.; Dupont, L.; Tarascon, J.-M. Nature 2000, 407, 496.

(25) Zhukovskii, Y. F.; Balaya, P.; Kotomin, E. A.; Maier, J. Phys. Rev. Lett. 2006, 96, 058302. 
(26) Sharma, N.; Reddy, M. V.; Du, G.; Adams, S.; Chowdari, B. V. R.; Guo, Z.; Peterson, V. K. J. Phys. Chem. C 2011, 115, 21473.

(27) Otte, H. M.; Montague, W. G.; Welch, D. O. J. Appl. Phys. 1963, $34,3149$.

(28) Bragg, W. L. Phys. Z. 1922, 23, 114.

(29) Berliner, R.; Fajen, O.; Smith, H. G.; Hitterman, R. L. Phys. Rev. B 1989, 40, 12086.

(30) Kang, B.; Ceder, G. Nature 2009, 458, 190.

(31) Laffont, L.; Delacourt, C.; Gibot, P.; Wu, M. Y.; Kooyman, P.; Masquelier, C.; Tarascon, J.-M. Chem. Mater. 2006, 18, 5520.

(32) Delmas, C.; Maccario, M.; Croguennec, L.; Le Cras, F.; Weill, F. Nat. Mater. 2008, 7, 665.

(33) Brunetti, G.; Robert, D.; Bayle-Guillemaud, P.; Rouviere, J. L.; Rauch, E. F.; Martin, J. F.; Colin, J. F.; Bertin, F.; Cayron, C. Chem. Mater. 2011, 23, 4515.

(34) Bai, P.; Cogswell, D. A.; Bazant, M. Z. Nano Lett. 2011, 11, 4890.

(35) Weichert, K.; Sigle, W.; van Aken, P. A.; Jamnik, J.; Zhu, C.; Amin, R.; Acartürk, T.; Starke, U.; Maier, J. J. Am. Chem. Soc. 2012, 134, 2988.

(36) Ellis, B.; Penny, L. K.; Ryan, D. H.; Nazar, L. F. J. Am. Chem. Soc. 2006, 128, 11416 .

(37) Srinivasan, V.; Newman, J. Electrochem. Solid-State Lett. 2006, 9, A110.

(38) Sharma, N.; Du, G.; Studer, A. J.; Guo, Z.; Peterson, V. K. Solid State Ionics 2011, 199-200, 37.

(39) Du, G.; Sharma, N.; Kimpton, J. A.; Jia, D.; Peterson, V. K.; Guo, Z. Adv. Funct. Mater. 2011, 21, 3990. 